УДК $338.242 ; 339.972$

\title{
ЭНДОГЕННЫЕ ФАКТОРЫ, ОБУСЛОВЛИВАЮЩИЕ РАЗВИТИЕ ПРОМЫШЛЕННОЙ ПОЛИТИКИ БЕЛАРУСИ В СОВРЕМЕННЫХ УСЛОВИЯХ
}

\author{
В. Л. ГУРСКИЙ \\ кандидат экономических наук, доцент, зав. кафедрой экономики \\ БИП-Институт правоведения, г. Минск
}

\begin{abstract}
Аннотация
Наличие определенных противоречий на нынешнем этапе развития промышленности Беларуси требует пересмотра основных направлений и инструментов промышленной политики. На основании учета особенностей белорусской модели экономического развития выявлены и систематизированы факторы, обусловливающие формирование и эволюцию промышленной политики в Беларуси. Представлен механизм действия факторов, обусловливающих формирование и эволюцию промышленной политики в Республике Беларусь.
\end{abstract}

Abstract

The presence of certain contradictions at the current stage of development of Belarusian industry requires a revision of guidelines and instruments of industrial policy. Taking into account the peculiarities of the Belarusian model of economic development, factors determining the industrial policy of Belarus it were identified and systematized. The article also describes mechanism of the factors responsible for the formation and evolution of industrial policy in the Republic of Belarus was represented.

\section{ВВЕДЕНИЕ}

Наличие определенных противоречий на нынешнем этапе развития промышленности Беларуси требует пересмотра основных направлений и инструментов промышленной политики. Исторически сложившаяся в Беларуси индустриальная структура экономики, экспортная ориентация ее производства наряду с практически полной ресурсносырьевой зависимостью от импорта в условиях ускорения НТП и глобализации мировой экономики, обострения экономических и политических противоречий между соседними государствами как никогда остро ставит задачу построения эффективной промышленной политики в соответствии с национальными особенностями и интересами. При этом, на наш взгляд, целесообразно говорить не об ослаблении государственного воздействия на экономику, а о коррекции целей, задач и инструментов такого воздействия, что в свою очередь требует глубокого анализа факторов, обусловливающих существование, эволюцию и реализацию промышленной политики.

Экономическая сущность промышленной политики страны раскрывается в трудах А. Татаркина [1], В. Завадникова [2], А. Нещадина [3], И. Липсица [4], С. Бадмаева [5], Е. Потаповой, С. Толкачева [6], Д. Львова [7], О.С. Сухарева [8]. Однако они специализируются только на российской экономике. Изменение задач промышленной политики в глобализирующейся экономике описано в работах Л. Бляхмана [9], Ю. Малышева [10], В. Княгинина, П. Щедровицкого [11], М. Кротова [12]. Особенности промышленной политики при переходе к рынку в России исследуются в работах М. Барабанова [13], Е.М. Примакова [14], изучением приоритетов промышленной политики занимались И. Рукина [15], Д. Рубвальтер [16], Д. Сотников [17]. Теоретические основы региональной промышленной политики, практика ее формирования и механизм реализации представлены в исследованиях И. Гришина [18], К. Титова [19], А. Кузнецова, А. Татаркина [20], Р. Чененовой, А. Гребенкина, О. Романовой [21], Б. Алиева [22]. Вопросами эволюции государственной промышленной политики в СССР и Российской Федерации занимались Е. Бодрова, М. Гусарова, В. Калинов [23]. Взаимодействие социально-экономических интересов при формировании промышленной политики исследовал И.Ю.Кушнир [24].

В Беларуси вопросы государственного регулирования и прогнозирования развития промышленного комплекса изучали С. Миксюк [25], И. Телеш, М. Мясникович [26], А. Филипцов [27], С.А.Пелих [28]. Вопросы обеспечения экономической безопасности промышленного комплекса на стадии его роста проработаны в трудах А. Н. Сенько [29], методика прогнозирования важнейших показателей развития промышленного комплекса разработана в работах И. Л. Телеш [30].

Однако, научные разработки в этой области в основном раскрывают вопросы, так или иначе связанные с промышленной политикой, не углубляясь в суть данной экономической категории. В этой связи, цель данного исследования - охарактеризовать внутренние (эндогенные) факторы, обусловливающие промышленную политику страны, определить механизм их воздействия на эволюцию промышленной политики Республики Беларусь и стран ЕАЭС в современных условиях.

\section{РЕЗУЛЬТАТЫ И ИХ ОБСУЖДЕНИЕ}

Исходя из понимания промышленной политики как системы принципов и инструментов и целей государственной координации экономического процесса в промышленности, посредством разработки долгосрочной экономической стратегии развития национального промышленного комплекса, при установлении факторов, обусловливающих существование, эволюцию и реализацию промышленной политики, следует выделять внешние (экзогенные) и внут- 
ренние (эндогенные) факторы. Под экзогенными факторами понимаются такие социальные и экономические процессы, которые, во-первых, являясь внешними по отношению к промышленной политике, в тоже время непосредственно связаны с последней, и, во-вторых, реально предопределяют изменение и реализацию промышленной политики. В свою очередь, под эндогенными факторами, предопределяющими промышленную политику, понимаются социальные и экономические факторы внутреннего по отношению к промышленной политике происхождения. Экзогенные и эндогенные факторы промышленной политики тесно связаны друг с другом и взаимообусловлены. В ряде случаев между ними невозможно провести четкую грань.

В качестве внутренних (эндогенных) экономических факторов, обусловливающих промышленную политику, необходимо выделять: количественные и качественные изменения трудовых ресурсов; объемы и легкость доступа к инвестиционным ресурсам; динамику предпринимательских ресурсов; имеющиеся материально-технические и технологические ресурсы, в том числе разработанные и применяемые отечественные технологии; имеющиеся в наличии и используемые средства производства; экологическое состояние промышленного производства и окружающей среды; уровень развития отечественной фундаментальной и прикладной науки, разработки которой предназначены для индустриального сектора народного хозяйства; развитость системы государственного регулирования экономики и способность государства мобилизовать экономические ресурсы для проведения модернизации промышленности. Именно эти факторы предлагается рассмотреть подробнее.

В качестве первого эндогенного фактора, обусловливающего промышленную политику, выступает количественное и качественное изменение трудовых ресурсов. Как известно, функциональная роль хозяйственных ресурсов различна. При этом главным фактором в производственном процессе выступают трудовые ресурсы. А.П. Морова определяет трудовую деятельность «как целесообразную общественно необходимую и практически полезную производственную деятельность человека, направленную на обеспечение экономической жизненности общества и его членов» [31]. Исходя из такого понимания трудовых отношений, становится очевидным, что именно труд является единственным фактором создания накоплений для расширения общественного воспроизводства, поскольку именно он создает прибавочный продукт (только труд в состоянии создавать стоимость большую, чем он стоит сам), а последний является единственным источником накоплений. Таким образом, рабочая сила является главной производительной силой общества. При этом за трудовые ресурсы между названными отраслями и входящими в них предприятиями постоянно ведется конкурентная борьба. При этом необходимо учитывать, что кроме рабочей силы в трудовые ресурсы включается часть трудоспособного населения, которая по многим причинам не принимает участия в процессе труда, но при определенных условиях может быть в нем задействована.

В современной экономике, под воздействием НТР постоянно происходят качественные изменения в структуре рабочей силы, задействованной в народном хозяйстве - сокращается потребность в работниках, занятых физическим и ручным трудом, увеличивается потребность в высококвалифицированных специалистах.

Количественное и качественное изменение трудовых ресурсов выступает фактором, обуславливающим промышленную политику в той мере, в которой это влияет на систему принципов и инструментов государственной координации экономического процесса формирования и реализации стратегии развития национального промышленного комплекса, а именно:

во-первых, перспективы модернизации промышленного комплекса напрямую зависят от количества и качества рабочей силы, которая может быть использована в этом процессе. Можно писать самые совершенные стратегии развития промышленности, но если при этом мы не сможем обеспечить промышленность необходимым количеством рабочей силы, причем определенной квалификации, то все эти планы так и останутся не реализованными. Соответственно качественные изменения рабочей силы в направлении роста ее квалификации являются необходимым условием и объективным ограничителем проводимой промышленной политики;

во-вторых, даже при наличии трудовых ресурсов, требуемых для реализации на практике эффективной промышленной политики, это само по себе не обозначает, что люди придут работать именно на промышленное производство. В рыночной экономике наемный работник будет выбирать лучшие условия найма, а в промышленности, даже после ее современной модернизации, труд по-прежнему остается достаточно тяжелым, поэтому для привлечения рабочей силы в индустриальный сектор народного хозяйства необходимо, чтобы работа в нем была экономически выгодна и социально привлекательна. Таким образом, подготовка рабочей силы для промышленности и удержание ее в ней будет также являться объективным ограничителем промышленной политики. Причем, в рыночной экономике по мере успешности создания современной сверх индустриальной системы конкуренция между промышленностью и сферой услуг за получение квалифицированных работников будет только возрастать;

в-третьих, на формирование и реализацию промышленной политики будут оказывать существенное влияние и такие показатели как уровень использования трудовых ресурсов, степень использования годового фонда рабочего времени, степень использования дневного рабочего времени. В результате возникает управленческая дилемма: либо продолжать увеличивать количество трудовых ресурсов, используемых в промышленности, либо предпринимать усилия по повышению фактического использования рабочего времени. Реализация любого из этих направлений также будет оказывать влияние на промышленную политику.

В качестве второго фактора, обусловливающего промышленную политику, выступают объемы и легкость доступа к инвестиционным ресурсам. Как правило, экономисты определяют инвестиционные ресурсы как «денежные средства и иные активы, привлекаемые для осуществления вложений в объекты инвестирования» [32]. Для развития национального промышленного комплекса необходимо не просто получение какого-то количества инвестиционных ресурсов (хотя это тоже очень важно), но и получение этих ресурсов через такие источники и механизмы их финанси- 
рования, которые обеспечивали бы стабильность и своевременность их поступления в сочетании с экономической эффективностью. Т.е. они должны быть достаточно дешевыми для того, чтобы способствовать поддержанию конкурентоспособности выпускаемой промышленной продукции на мировых рынках. Поскольку дорогие финансовые ресурсы ведут к снижению конкурентоспособности продукции тех коммерческих организаций, которые их используют. Таким образом, объемы и легкость доступа к инвестиционным ресурсам выступают фактором, обусловливающим промышленную политику, за счет того что оказывают непосредственное влияние на последнюю в зависимости от того, из каких источников финансируются инвестиции и как изменяется доля этих источников в общем объеме финансирования. Такими укрупненными источниками выступают собственные, заемные и привлекаемые. Причем укрупненные источники в свою очередь также дифференцируются на более мелкие (элементарные). В рамках промышленной политики все источники финансирования инвестиций в народном хозяйстве должны быть стратегически учтены, и на этой основе необходимо через сочетание рыночных механизмов (с использованием активного государственного управления этим процессом) выбрать те из них, которые смогут обеспечить необходимое финансирование инвестиционных ресурсов в целях совершенствования структуры национальной экономики и промышленного комплекса, а также поддержания конкурентоспособности выпускаемой промышленной продукции на мировых рынках. При координации экономического процесса в рамках промышленной политики следует учитывать, что необходима его координация с социальной политикой, оборонительной политикой и т.д. К механизмам действия рассматриваемого фактора, воздействующего на промышленную политику, могут быть также отнесены: стимулирование инвестиций в форме кредитов, субсидий, различных налоговых льгот; системы государственных заказов и закупок; меры по регулированию прямых иностранных инвестиций.

В качестве третьего фактора, обусловливающего промышленную политику, выступает динамика (изменение) предпринимательских ресурсов. В данном случае под предпринимательским ресурсом понимается способность к предпринимательской деятельности. Этот фактор тесно связан с предыдущими факторами. Более того в современной рыночной экономике динамику предпринимательских ресурсов и динамику доступа к инвестиционным ресурсам в ряде случаев тяжело разделить. Вместе с тем, поскольку феноменологически природа этих факторов различна, то, по нашему мнению, их теоретическое разграничение будет способствовать системному пониманию обусловленности промышленной политики.

Поскольку в XXI веке предпринимательство как экономический ресурс становится все более важным в народном хозяйстве в целом, то возрастает и его влияние на промышленную политику. В литературе отмечается: «Предпринимательский ресурс (предпринимательский потенциал, предпринимательские способности, предпринимательство) - способность к эффективной организации взаимодействия таких экономических ресурсов, как труд, земля, капитал, знания, для осуществления хозяйственной деятельности. Этот ресурс реализуется в сфере менеджмента, т.е. при управлении деятельностью фирм и организаций. В состав предпринимательского ресурса входят его носители (предприниматели), инфраструктура (рыночные институты), этика и культура» [33]. Поскольку функциональное назначение этого ресурса в экономической системе общества заключается в возможности за счет инициативности и специфических профессионально-квалификационных способностей индивида организовывать комбинацию доступных экономических ресурсов таким образом, чтобы за счет этого получать дополнительный экономический эффект (добавленную стоимость, прибыль), то в случае его нехватки общество в целом, коммерческая организация будут нести дополнительные издержки.

Разумеется, нельзя идеализировать предпринимателя (носителя предпринимательского ресурса), поскольку в погоне за личной выгодой (прибылью) он может причинять экономический ущерб другим участникам рынка и обществу в целом. Вместе с тем как показывает теория и практика без предпринимательского ресурса невозможно функционирование рыночной экономике как таковой. Предпринимательский ресурс реализуется через систему менеджмента (управления) предприятием. Компонентами предпринимательского ресурса являются: предприниматели (его носители), предпринимательская инфраструктура (рыночные институты), этика и культура ведения бизнеса. Й. Шумпетер саму идею инновационного развития напрямую связывал с предпринимательством. По его мнению, без предпринимателя вообе невозможно инновационное развитие: «Внедряя в хозяйственную жизнь и реализуя на рынке на свой страх и риск новые изобретения, идеи, организационные мероприятия, предприниматель осуществляет тем самым нововведения (инновации)» [34]. Поэтому инновационная деятельность предпринимателей и является двигателем экономического развития.

В качестве фактора, обусловливающего промышленную политику, изменение предпринимательских ресурсов выступает постольку, поскольку степень развития рыночной инфраструктуры, этики и культуры бизнеса, предпринимательского духа общества напрямую влияет как на систему принципов и инструментов государственной координации экономического процесса посредством разработки долгосрочной экономической стратегии развития национального промышленного комплекса, так и на отдельные ее элементы.

В качестве четвертого и пятого факторов, обусловливающих промышленную политику, выступают имеющиеся материально-технические и технологические ресурсы, в том числе разработанные и применяемые отечественные технологии, а также имеющиеся в наличии и используемые средства производства. Поскольку воздействие этих факторов на промышленную политику очень взаимосвязано, то, по нашему мнению, будет целесообразно рассмотреть их вместе.

Материально-технические и технологические ресурсы, используемые в промышленности, в контексте промышленной политики очень динамичны. Последнее обусловлено тем, что под воздействием научно-технической революции эти ресурсы очень быстро морально устаревают и могут в относительно короткий период времени превратиться из фактора повышающего конкурентные преимущества отечественной промышленности в фактор их понижающий. 
Это естественным образом проистекает из феноменологической природы современного этапа научно-технического прогресса - научно-технической революции. Для характеристики изменения материально-технических и технологических ресурсов как фактора, обусловливающего промышленную политику, большое значение имеют изменения в средствах производства под влияние современной НТР, а именно то, что:

во-первых, качественно изменяются характер, содержание, квалификационно-профессиональные характеристики, разделение и кооперация труда за счет внедрения достижений науки в производство. При этом происходит увеличение доли высококвалифицированного, в ряде случаев узко специализированного, машинно-автоматизированного труда. Автоматизация и компьютеризация труда, введение автоматов значительно увеличивает производительность и качество труда;

во-вторых, увеличивается доля новых видов энергии - атомной, солнечной, морских отливов, земных недр, электромагнитной. Это сопровождается повсеместной заменой естественных материалов искусственными;

в-третьих, происходят революционные изменения в технологии производства. Все шире механическое воздействие на предмет труда (характерное для индустриального общества) заменяется физико-химическим и даже биологическим воздействием. Как результат на смену циклическим технологическим процессам приходят непрерывные поточные процессы. Соответственно «предъявляют и новые требования к орудиям труда (повышенная точность, надежность, способность к саморегулированию), к предметам труда (точно заданное качество, четкий режим подачи и т.д.), к условиям труда (строго заданные требования к освещенности, температурному режиму в помещениях, их чистоте и т.Д.)» [35];

в-четвертых, под воздействием общественно-функциональных инноваций меняется характер управления, а широкое использование автоматизированных систем управления качественно изменяет роль человека в системе управления и производственного контроля;

в-пятых, возрастает роль и значение информации в производственном процессе (в ряде случаев исследователи начинают определять новую стадию развития человечества как «информационное общество»), изменяются системы выработки, хранения, передачи и использования информации, что радикально повлияло на технологии принятия и оценки решений;

в-шестых, повышаются требования к профессиональной подготовке кадров.

Таким образом, под воздействие современной НТР имеющиеся материально-технические и технологические ресурсы оказывают постоянно изменяющее воздействие на промышленную политику, прежде всего за счет изменения технологических (в том числе информационных) инструментов государственной координации экономического процесса, в том числе посредством разработки долгосрочной экономической стратегии развития национального промышленного комплекса, т.к. меняется сам характер управления, широко используются автоматизированные системы, формируется инфраструктура информационного общества, изменяются системы выработки, хранения, передачи и использования информации. Это объективно изменяет формирование и реализацию промышленной политики.

Кроме того, в условиях ускорения реализации достижений науки в производство, для эффективности развития отечественного промышленного комплекса, возрастает значение научно-обоснованной долгосрочной экономической стратегии, включающей в себя учет новых технологических тенденций. Причем не только на стадии их внедрения, но и в контексте проблемы их быстрого получения. А поскольку смена технологий все более ускоряется, а получение их из-за рубежа становится все более проблематично (страны не хотят делиться своими технологическими преимуществами с потенциальными конкурентами), то возникает необходимость постоянного совершенствования механизмов быстрого и эффективного трансфера знания от организаций одного звена инновационного процесса другому, совместной работы рыночных и нерыночных структур по генерации новых знаний.

Как известно НТР сопровождается концентрацией капитала. Это обусловлено тем, что техническое перевооружение предприятий (особенно при переходе их к комплексной автоматизации производства с созданием автоматизированных цехов и заводов-автоматов) требует концентрации финансовых средств и значительных их затрат. Поэтому по мере развития национального промышленного комплекса перед Республикой Беларусь неизбежно возникнет проблема распределением ресурсов в целях совершенствования технико-технологического уровня промышленного комплекса на основе комплексной автоматизации производства. Последнее также будет влиять на формирование и реализацию промышленной политики.

В качестве шестого фактора, обусловливающего промышленную политику, выступает экологическое состояние промышленного производства и окружающей среды. Изменение экологического состояния промышленного комплекса показывает, какие последствия для общества имеет использование всей совокупности природных факторов. Под последними, как известно, понимаются географическое положение территории, количество и качество природных ресурсов, живой и неживой природы и иных составляющих географической среды. Деятельность промышленного комплекса не возможна без использования природных факторов, однако в процессе индустриального производства объективно ухудшается их состояние. То, насколько национальная промышленность оказывает негативное влияние на окружающую природу, непосредственно влияет на промышленную политику, поскольку рано или поздно, но общество вынуждено восстанавливать то природное окружение, которое было разрушено в период индустриализации. В современных условиях экологическое равновесие становится более хрупким, чем это было даже в прошлом веке, не говоря уже о XIX веке. Причем экологические последствия деятельности промышленного комплекса проявляются во влиянии на такие зоны окружающей среды как: атмосферный воздух, грунтовые и поверхностные воды, почва, шум и вибрации, а также электромагнитное и радиационное воздействие. 
Поскольку экологический потенциал страны, который «характеризует возможность сохранения и функционирования природных систем, рационального использования всех компонентов биосферы в интересах человека» [36], не может быть полностью оценен экономически, поскольку включает «невесомые полезности» природных ресурсов, то он должен быть учтен в промышленной политике в директивном порядке наряду с экономической оценкой природноресурсного потенциала. Таким образом, экологическое состояние промышленного производства и окружающей среды воздействует на промышленную политику, поскольку является важным хозяйственным ресурсом, который объективно ограничен, а соответственно при его распределении приходится выбирать, как именно он может быть использован, в целях совершенствования структуры национальной экономики и промышленного комплекса, повышения качества экономического роста.

В качестве седьмого фактора, обусловливающего промышленную политику, выступает уровень развития отечественной фундаментальной и прикладной науки, разработки которой предназначены для индустриального сектора народного хозяйства. Уровень развития национальной науки во многом предопределяется научным потенциалом страны, под которым сегодня понимается «совокупность ресурсов и условий осуществления научных исследований (фундаментальных и ориентированных фундаментальных)» [36]. Научный, научно-технический и инновационные потенциалы страны оказывают влияние на механизмы и инструменты формирования связей между экономическими субъектами для быстрого и эффективного трансфера знания от организаций одного звена инновационного процесса другому в промышленном комплексе страны. В случае не пропорционального развития одного из звеньев инновационного процесса (иначе можно сказать - недоразвития других или другого звеньев/звена) государство должно активно вмешиваться в этот процесс с целью его совершенствования. В противном случае будут возрастать издержки в процессе трансфера знания от организаций одного звена инновационного процесса другому в рамках национального промышленного комплекса, а соответственно это будет снижать (вплоть до критических значений) конкурентоспособность отечественных промышленных предприятий. При этом, необходимо постоянно совершенствовать промышленную политику для привлечения частного капитала в те или иные стадии трансфера технологий. Вместе с тем, поскольку как показывает мировой опыт, частные корпорации не заинтересованы в развитии фундаментальных исследований, государство должно брать на себя определение приоритетов развития отечественной фундаментальной науки, которые необходимо тесно увязывать со стратегией развития национального промышленного комплекса с учетом глобальных технологических тенденций.

В качестве следующего фактора, обусловливающего промышленную политику, выступает развитость системы государственного регулирования экономики и способность государства мобилизовать экономические ресурсы для проведения модернизации промышленности. Сегодня ни у одного серьезного ученого-экономиста не вызывает сомнение необходимость государственного вмешательства в экономическую жизнь страны. Вместе с тем до настоящего времени существует значительное разнообразие взглядов и подходов (иногда даже прямо противоположных) к механизмам, инструментам и границам этого вмешательства. Главным субъектом промышленной политики, ее мотором является государство. Как отмечается большинством исследователей: «Государство есть особый политико-правовой институт призванный регулировать и управлять посредством системы норм общественными отношениями, общезначимыми видами поведения и деятельности людей в обществе» [37]. На наш взгляд, государственное регулирование экономики может быть эффективно в том случае, если, во-первых, оно соответствует тем социально-экономическим вызовам, которые постоянно возникают перед обществом и народным хозяйством и, во-вторых, если существует возможность за счет государственного регулирования экономики быстрой и эффективной мобилизации экономические ресурсов на наиболее важных направлениях развитии народного хозяйства. Именно в этом контексте государственное регулирование экономики и способность государства мобилизовать экономические ресурсы для проведения модернизации промышленности выступает фактором промышленной политики.

В современной социальной философии сформировалось авторитетное мнение, в соответствии с которым нельзя рассматривать реальные объекты сначала в статике, а потом уже в динамике, поскольку и происхождение, и функционирование, и изменение этих объектов - это непрерывный процесс [38]. Поэтому все факторы, влияющие на промышленную политику, рассматриваются нами как одновременно обусловливающие ее существование и эволюцию. Очевидно, что в процессе реализации промышленная политика не остается неизменной, а это значит, что в нее постоянно, с той или иной быстротой, вносятся определенные изменения. Эти изменения (эволюция) могут касаться части, или всей системы принципов и инструментов государственной координации экономического процесса посредством разработки долгосрочной экономической стратегии развития национального промышленного комплекса.

В целом, механизм действия факторов, обуславливающих существование и эволюцию промышленной политики в Республике Беларусь, схематически отражена на рисунке 1. 
ОСОБЕННОСТИ НАЦИОНАЛЬНОЙ ЭКОНОМИЧЕСКОЙ СИСТЕМЫ

особенности национальной модели экономического развития

особенности протекания современного этапа научно-технической революции особенности изменения сущностных характеристик и потребностей хозяйствующих субъектов

особенности переходного характера хозяйственной системы и реформаторско-эволюционного типа самого переходного процесса в экономике Беларуси

\section{Внешние факторы}

геоэкономическое развитие
$\begin{aligned} & \text { зависимость отечественной промышленности от } \\ & \text { импорта экономических ресурсов }\end{aligned}$
$\begin{aligned} & \text { состояние и динамика внешних рынков сбыта } \\ & \text { продукции промышленного комплекса }\end{aligned}$

\begin{tabular}{|l|}
\hline международные технологические трансферты \\
научно-техническая политика \\
социальная политика \\
старые и новые внешние риски и угрозы \\
\hline
\end{tabular}
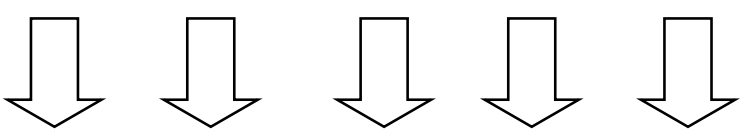

\section{Внутренние факторы}

количественное и качественное изменение трудовых ресурсов

объемы и легкость доступа к инвестиционным ресурсам

динамика (изменение) предпринимательских ресурсов

имеюшиеся материально-технические и технологические ресvрсы

экологическое состояние промышленного производства и окружающей среды

уровень развития отечественной фундаментальной и прикладной науки для индустриального сектора

развитость системы государственного регулирования экономики и способность государства мобилизовать экономические ресурсы для проведения модернизации промышленности

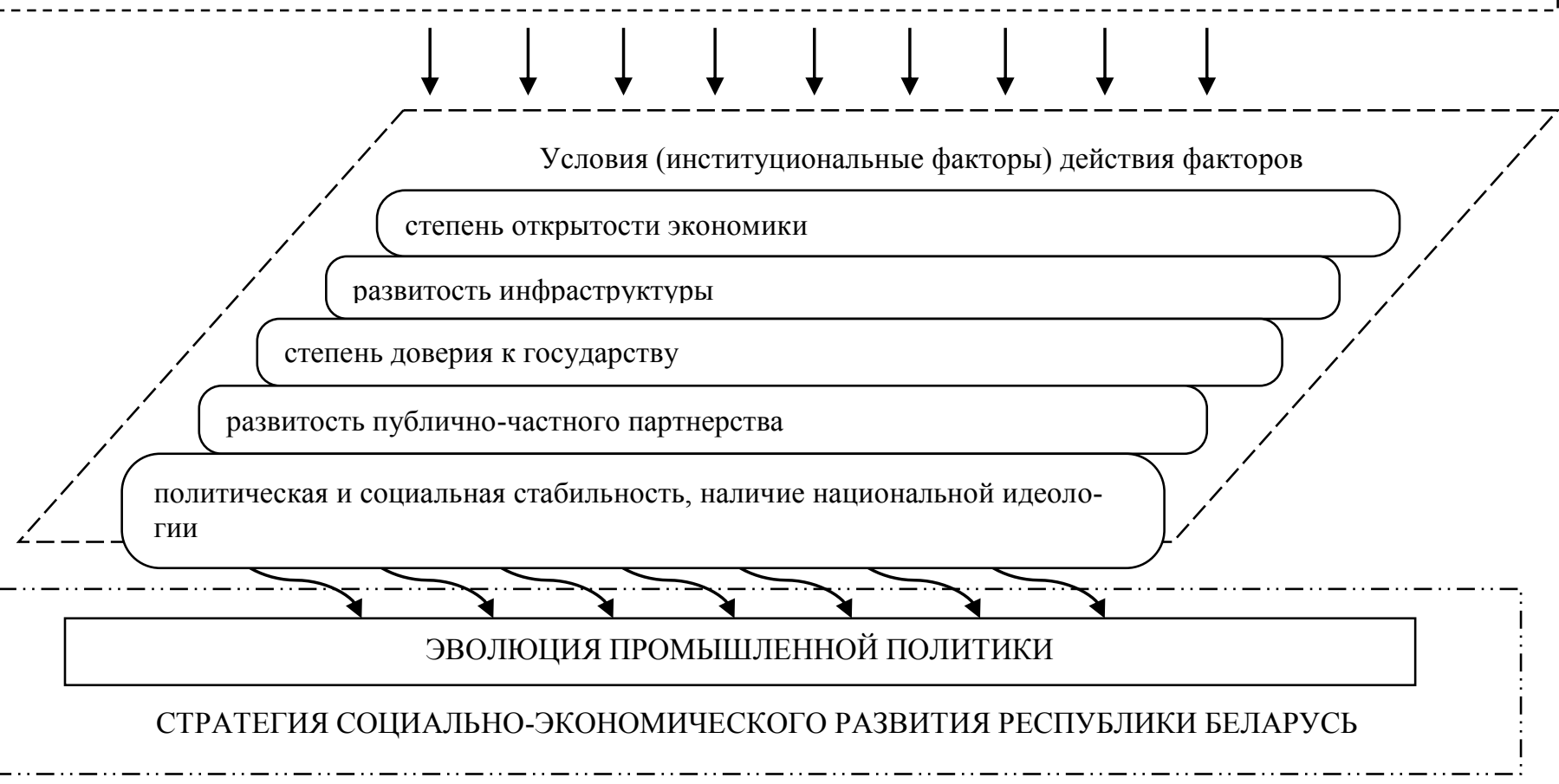

Рисунок 1 - Механизм действия факторов, обуславливающих существование и эволюцию промышленной политики в Республике Беларусь 
Под эволюцией промышленной политики нами понимается процесс ее изменения (преимущественно необратимого характера), протекающий в ней. Под моделью в данном случае понимается упрощённое воспроизведение представления реального устройства и/или протекающих в нём процессов, явлений.

Специфика действия эндогенных факторов, обусловливающих промышленную политику, во многом предопределяется социально-институциональными условиями, к которым следует отнести: степень открытости экономики; развитость инфраструктуры; степень доверия к государству; развитость публично-частного партнерства; политическая и социальная стабильность; наличие национальной идеологии. Прямое действие факторов трансформируется социально-институциональными условиями, поэтому воздействие факторов на формирование и эволюцию промышленной политики будет специфичным для каждой экономической системы.

\section{ВЫВОДЫ}

Таким образом, наличие определенных противоречий на нынешнем этапе развития промышленности Беларуси требует пересмотра основных направлений и инструментов промышленной политики, что в свою очередь требует глубокого анализа факторов, обусловливающих ее существование, эволюцию и реализацию. Среди факторов, обусловливающих промышленную политику, нами предлагается выделять внешние (экзогенные) и внутренние (эндогенные) факторы. Под экзогенными факторами понимаются такие социальные и экономические процессы, которые, вопервых, являясь внешними по отношению к промышленной политике, в тоже время непосредственно связаны с последней, и, во-вторых, реально предопределяют изменение и реализацию промышленной политики. В свою очередь, под эндогенными факторами, предопределяющими промышленную политику, понимаются социальные и экономические факторы внутреннего по отношению к промышленной политике происхождения. Экзогенные и эндогенные факторы промышленной политики тесно связаны друг с другом и взаимообусловлены. В ряде случаев между ними невозможно провести четкую грань.

В качестве внутренних (эндогенных) экономических факторов, обусловливающих промышленную политику, необходимо выделять: количественные и качественные изменения трудовых ресурсов; объемы и легкость доступа к инвестиционным ресурсам; динамику предпринимательских ресурсов; имеющиеся материально-технические и технологические ресурсы, в том числе разработанные и применяемые отечественные технологий; имеющиеся в наличии и используемые средства производства; экологическое состояние промышленного производства и окружающей среды; уровень развития отечественной фундаментальной и прикладной науки, разработки которой предназначены для индустриального сектора народного хозяйства; развитость системы государственного регулирования экономики и способность государства мобилизовать экономические ресурсы для проведения модернизации промышленности. Прямое действие факторов трансформируется социально-институциональными условиями, поэтому воздействие факторов на формирование и эволюцию промышленной политики будет специфичным для каждой экономической системы.

\section{ЛИТЕРАТУРА}

1. Татаркин, А.И. Промышленная политика и механизмы ее реализации: системный подход / А.И. Татаркин, О.А. Романова // Экономика региона. 2007. № 3. С. 19-31.

2. Завадников, В. О промышленной политике Российской Федерации / В. Завадников // Общество и экономика. - 2007. - № 2-3. - С.5-39.

3. Нещадин, А. О реструктуризаџии российской промышленности / А. Нещадин // Проблемы теории и практики управления. - 2000. - №4.

4. Липсиц, И.В. Экономика: Учебник для вузов, изд. 5-е // Издательство: Омега-Л , 2010, 375 с.

5. Бадмаев, С.В. Формирование модели инновационно-промышленной политики России / С.В. Бадмаев // ЭКО №4.2007. - С. 17 -52.

6. П Потапова, Е.Н., Толкачев, С. А. Промышленная политика и государственное регулирование экономики (Современные аспекты российской практики). [Электронный ресурс] / M., 2006. - [Научное издание (монография)]. - Режим доступа: - http://kapital-rus.ru/articles/article/184742

7. Львов, Д.С. Новая промышленная политика России / Д.С. Львов // Экон. наука соврем. России. - 2007. - N 3. - C. 9-12.

8. Сухарев, О.С. Индустриальная политика и развитие промышленных систем / О.С. Сухарев, Е.Н. Стрижакова // Национальные интересы: приоритеты и безопасность. - 2014. - № 15. - С. 2-21

9. Бляхман, А.А. Промышленная политика - основа перехода к новой модели экономического роста / А.А.Бляхман // Проблемы современной экономики. - 2013. - №1. - С. 7-17.

10. Малышев, Ю.А. Новая парадигма региональной промышленной политики / Ю.А. Малышев, А.И. Камалов // Вестник Пермского университета. Серия: Экономика. - 2011. - №1. - С. 7-23.

11. Княгинин, В. Н. Промышленная политика России - кто оплатит издержки глобализации? / В.Н. Княгинин, П. Г. Щедровицкий // Современная национальная политика России. Вып. 1. — М.: ИКЦ «Академкнига», 2004. C. $106-108$.

12. Кротов, М.И. Проблемы модернизации экономики России в условиях евразийской интеграции / М.И. Кротов // Проблемы современной экономики. - 2013. - №1. - С. 18-21.

13. Барабанов, М. Промышленная политика России / М. Барабанов // Международная экономика и международные отношения. 1994. №1. С. 92-102. 
14. Примаков, Е.М. Государственная политика промышленного развития: От проблем к действиям / Под ред. Е.М. Примакова, В.Л. Макарова. - Москва: Наука, 2004

15. Рукина, И. О приоритетах промышленной политики / И.О. Рукина // Экономист. - 2003. - № 12. - С.6164.

16. Рубвальтер, Д. Промышленная политика: проблемы выработки приоритетов / Д. Рубвальтер // Власть. - 2007. - № 12. - С.27-37.

17. Сотников, Д.М. Критерии выбора приоритетов государственной промышленной политики / Д.М. Сотников // «Вестник МГУ», Серия «Экономика», №1, 2007 г. - С. 17 -32.

18. Гришин, И. А. Региональная промышленная политика развития малых предприятий: дис. ... д-ра. экон. наук: 08.00.05 / И. А. Гришин. - Волгоград, 2007. - 359 с.

19. Титов, К.Э. Региональная промышленная политика: цели, задачи, приоритеты / К.Э. Титов // Вопросы экономики. - 2007. - №5. - С. 264- 266.

20. Татаркин, А.И. Региональная промышленная политика: от макроэкономических условий формирования к механизмам реализации / А.И. Татаркин, О.А. Романова, Р.И. Чененова, И.В. Макарова. - Москва: ЗАО «НПО «Изд-во «Экономика», 2012. - 360 с.

21. Татаркин, А.И. Экономико-технологическое развитие региональных промышленных систем: теория, методология, практика / А.И. Татаркин, О.А. Романова, А.В. Гребенкин, В.В. Акбердина; под ред. А.И. Татаркина. Москва: Наука, 2011. - 353c.

22. Алиев, Б.Х. Формирование и реализация промышленной политики в депрессивном регионе: дис. ... дра экон. наук: 08.00.05 / Б.Х. Алиев. - Махачкала, 2001. - 265 с.

23. Бодрова, Е.В. Эволюция государственной промышленной политики в СССР и Российской Федерации: монография / Е.В. Бодрова, М.Н. Гусарова, В.В. Калинов; под общ. ред. Е.В. Бодровой. - М., 2014. - 940 с.

24. Кушнир, И. Ю. Взаимодействие социально-экономических интересов при формировании промышленной политики: Дис. ... канд. экон. наук : 08.00.05 / И. Ю. Кушнир. - Москва, 2003163 с.

25. Миксюк, С.Ф. Концептуальные и методические подходы к среднесрочному прогнозированию развития промышленного комплекса Республики Беларусь / С.Ф. Миксюк, И.Л. Телеш // Белорусский экономический журнал. - 2008. - № 1. - С. 36-45

26. Мясникович, М.В., Антонова Н.Б., Нехорошева Л.Н. Государственное регулирование инновационной деятельности: Уч. пос. - Мн.: Академия управления при Президенте Республики Беларусь, 2005. - 235 с.

27. Филипцов, А.М. Отраслевая политика и экономическое развитие: проблемы теории. - Горки: Белорусская государственная сельскохозяйственная академия. - 2006. - 234 с. - [Научное издание (монография)].

28. Пелих, С.А. Концептуальные основы формирования промышленной политики в Республике Беларусь. Институциональная политика или создание «рамочных» условий хозяйствования / С.А.Пелих // Государственное регулирование экономики и повышение эффективности деятельности субъектов хозяйствования: XI Междунар. науч.практ. конф., Минск, 16-17 апр. 2015 г. :сб. науч. ст. / редкол.: д-р физ.-мат. наук, проф. И.И. Ганчеренок (пред.) [и др.]. - Минск: Акад. упр. при Президенте Респ. Беларусь, 2015. - С. 267-270.

29. Сенько, А. Н. Обеспечение экономической безопасности промышленного комплекса Республики Беларусь на стадии его роста: дис. ... д-ра эконом. наук: 08.00.05 / А. Н. Сенько. - Минск, 2008. - 245 л.

30. Телеш, И. Л. Совершенствование прогнозирования важнейших показателей развития промышленного комплекса Республики Беларусь: Дис. ... канд. эконом. наук: 08.00.05 / И. Л. Телеш. - Минск, 2010. - 112 л.

31. Морова, А. П. Социальная политика в сфере трудовых отношений. / А.П. Морова. - Мн.: ИСПИ, 2000. - C. 7.

32. Рыковский, И.М. Источники финансирования реальных инвестиций, их классификация / Электронный ресурс:

http://www.rusnauka.com/10. ENXXIV 2007/Economics/21802.doc.htm. - Режим доступа 03.06.2015

33. Мировая экономика: Учебник / Под ред. проф. А.С. Булатова. - Москва: Экономистъ, 2005. - 734 с.

34. Shionoya, Y. Shumpeter and his surroundings: on overview // Schumpeter and the Idea of Social Science: A Metatheoretical Study. — Cambridge: Cambridge University Press, 2007. — P. 14. — 354 p.

35. Философия техники: учебное пособие / И.В. Вишев, Е.В. Гредновская, Л.М. Григорьева, А.А. Дыдров. - Челябинск: Издательский центр, 2014. - 251 с.

36. Национальная экономика Беларуси: Потенциалы. Хозяйственные комплексы. Направления развития. Механизмы управления: учеб. пособие / под общ. ред. В.Н. Шимова. - Мн.: БГЭУ, 2005

37. Политико-административное управление: Учебник Российской академии государственной службы при Президенте Российской / Под общ. ред. В.С.Комаровского, Л.В.Сморгунова. - Москва: Изд-во РАГС, 2004. - 496 с. (стр. 128)

38. Штомпка, П. Социология социальных изменений. - М.: Аспект Пресс, 1996. - С. 19.

Статья поступила в редакцию 18 июня 2015 2. 